\title{
Practice of contemporary dance promotes stochastic postural control in aging
}

\author{
${ }^{1}$ Groupe de Recherche Apprentissage et Contexte, Ecole des Hautes Etudes en Sciences Sociales, Paris, France \\ ${ }^{2}$ The Neuropsychological Laboratory, CNS-Fed, Paris, France \\ ${ }^{3}$ Université Paris Descartes, Paris, France \\ ${ }^{4}$ Research Institute of Health and Welfare, Kibi International University, Okayama, Japan
}

Lena Ferrufino ${ }^{1,2}$, Blandine Bril ${ }^{1}$, Gilles Dietrich ${ }^{1,3}$, Tetsushi Nonaka ${ }^{1,4}$ and Olivier A. Coubard ${ }^{2 *}$

\section{Edited by:}

Idan Segev, The Hebrew University of Jerusalem, Israel

\section{Reviewed by:}

Lutz Jäncke, University of Zurich, Switzerland

Laurence Bernard Demanze, UMR

6149 CNRS, France

\section{*Correspondence:}

Lena Ferrufino, Groupe de Recherche Apprentissage et Contexte, Ecole des Hautes Etudes en Sciences Sociales, 190 avenue de France, 75013 Paris, France.

e-mail: lenaferrufino@gmail.com; Olivier A. Coubard, The

Neuropsychological Laboratory,

CNS-Fed, 39 rue Meaux, 75019 Paris, France.

e-mail: olivier.coubard@cns-fed.com
As society ages and the frequency of falls increases, counteracting gait and posture decline is a challenging issue for countries of the developed world. Previous studies have shown that exercise and hazard management help to improve balance and/or decrease the risks for falling in normal aging. Motor activity based on motor-skill learning, particularly dance, can also benefit balance and decreases falls with age. Recent studies have suggested that older dancers have better balance, posture, or gait than non-dancers. Additionally, clinical or laboratory measures have shown improvements in some aspects of balance after dance interventions in elderly trainees. This study examined the impact of contemporary dance (CD) and of fall prevention (FP) programs on postural control of older adults. Posturography of quiet upright stance was performed in 41 participants aged 59-86 years before and after 4.4-month training in either CD or FP once a week. Though classical statistic scores failed to show any effect, dynamic analyses of the center-of-pressure displacements revealed significant changes after training. Specifically, practice of $C D$ enhanced the critical time interval in diffusion analysis, and reduced recurrence and mathematical stability in recurrence quantification analysis, whereas practice of FP induced or tended to induce the reverse patterns. Such effects were obtained only in the eyes open condition. We suggest that $C D$ training based on motor improvisation favored stochastic posture inducing plasticity in motor control, while FP training based on more stereotyped behaviors did not.

Keywords: aging, postural control, motor activity, contemporary dance, flexibility, plasticity

\section{INTRODUCTION}

Balance is a complex function achieved by (i) multi-sensory integration of visual, vestibular, and somesthetic afferences, (ii) central motor control, and (iii) context-specific response generation (Nashner, 1976). In aging, changes occur in visual (Lord, 2006), vestibular (Kristinsdottir et al., 2001), proprioceptive and exteroceptive inputs (Famula et al., 2008), central processing (Horak, 2006), and muscular effectors (Schultz, 1995). Reduced sensory cue congruency, increased visual dependency and motor tone cause decreased balance and unsteady gait (Judge, 2003). Balance and gait disorders are the second risk factor for falls in aging with dramatic morbidity and mortality consequences (Rubenstein, 2006). Developing strategies to prevent falls is thus a major issue of public health to preserve a successful aging (Judge, 2003).

Several programs have been proposed to improve balance and reduce falls in aging: exercise, environmental inspection, and hazard management (Day et al., 2002; Rubenstein, 2006). Home- or center-based exercise interventions have focused on the training of lower limb strength and of balance (Robertson et al., 2001), walking and stair climbing with weights, joint reinforcement, functional balance (King et al., 2002), or flexed posture (Benedetti et al., 2008), and their efficacy has been assessed using clinical (Berg et al., 1995; Rossiter-Fornoff et al., 1995) or laboratory (Benedetti et al., 2008) measures. Tai Chi and dance have also been suggested to be promising programs to develop balance and prevent falls in older adults (American Geriatrics Society, British Geriatrics Society, and American Academy of Orthopaedic Surgeons Panel on Falls Prevention, 2001; Judge, 2003).

Cross-sectional studies have shown that older social dancers (i.e., ballroom, in line, or pairs) have better balance, a more stable walking pattern (Verghese, 2006), faster leg reaction time, and better postural stability (Zhang et al., 2008) than non-dancers. In an intervention study, Shigematsu et al. (2002) showed that 20 women aged $72-87$ years trained to 36 sessions of dancebased aerobic exercise had better balance in single-leg stance and functional reach, and higher locomotion in walking around two cones, compared to untrained controls. After only six sessions of a Laban-based movement program, Hamburg and Clair (2003) observed that 36 adults aged 63-86 years increased their balance in time up-and-go and standing toe/heel lifts, and their velocity and cadence gait. Alpert et al. (2009) reported a progressive balance improvement in the Sensory Organization Test in 13 women aged 52-88 years performing jazz dance for 15 weeks. Hui et al. (2009) compared 52 adults aged 68 years in average trained to low impact aerobic dance (cross and Cha-cha steps) to 42 untrained controls. After 24 sessions, dancers had improved their dynamic balance in time up-and-go, but not their static balance as assessed by the Physical Performance Battery. 
The purpose of this study was to examine the effects of two motor activities sought to improve balance, contemporary dance (CD), and fall prevention (FP), on postural control of older adults. To achieve this goal, we used a force platform and measured the center-of-pressure ( $\mathrm{CoP})$ displacements in upright stance, eyes open, and eyes closed, before and after 4.4 months of training. In addition to classical statistic scores (length, areas, mean, and variance velocities, Romberg quotient, fractal dimension), we examined the dynamics of CoP displacements using stabilogram diffusion analysis (SDA; Collins and De Luca, 1993) and recurrence quantification analysis (RQA; Riley et al., 1999). In SDA, Collins and De Luca (1993) have shown that the trajectories of the mean square displacement plotted as a function of time interval are different from those expected for a Brownian motion. Indeed, the SD plot changes slope after a critical point thus exhibiting short- and long-term regions which, from a physiological viewpoint, respectively approximate open- and closed-loop control mechanisms. RQA is a non-linear method that yields, among others, the degree of autocorrelation measured by recurrence (\%REC), determinism vs. randomness (\%DET), and mathematical stability measured by maximal line diagonal (MAXL). RQA is an empirical method rather than a theoretical approach. Thus RQA measures are not considered as absolute but must be taken with respect to the levels of a manipulated data (e.g., before and after a training; Riley et al., 1999).

Regarding the influence of the sensory context (i.e., vision), SDA has shown two patterns. Visual input has caused either a decrease or an increase in stochastic activity, which has been interpreted in both schemes to serve to decrease the stiffness of the musculoskeletal system (Collins and De Luca, 1995). In RQA, the deterministic structure of CoP displacements increase with the eyes closed as compared to eyes open (Riley et al., 1999). With regards to age, critical mean square displacement and critical time interval increase with age in SDA (Collins et al., 1995). While no systematic study has been done on the aging effect on RQA measures (Riley et al., 1999), \%REC, \%DET, and MAXL are known to increase with decreasing behavioral flexibility (Riley et al., 1999; Webber and Zbilut, 2005). Consistent, Parkinson's disease yield higher values of \%REC, \%DET, and MAXL compared to healthy controls (Schmit et al., 2006), while ballet dancers have lower RQA values than track athletes (Schmit et al., 2005).

In this study, we expected the CD program to favor stochastic posture in SDA and postural flexibility in RQA in higher proportion than the FP program. As both training programs were mostly performed eyes open, such effects were expected to be observed in the eyes open condition. To justify this hypothesis, we suggest that normal aging is accompanied by inflexibility as a result of decreasing motor and cognitive control with age. Indeed, attentional control show more precocious and larger decline than other functions in older adults (Bherer et al., 2004), consistent with an early decline of prefrontal areas of the brain (Rajah and D'Esposito, 2005; Raz and Rodrigue, 2006). As a correlate, motor control has been shown to decline with age with pejorative consequences for gait and posture (de Bruin and Schmidt, 2010; Theill et al., 2011). In a recent study, Coubard et al. (2011) showed that the practice of CD improved switching attention (i.e., cognitive flexibility), which was not the case of that of FP or of Tai Chi Chuan. As CD focused on motor improvisation while FP and Tai Chi Chuan taught motor routines, it was suggested that CD may have worked as a training for change, thus inducing plasticity in flexible attention (Coubard et al., 2011). Yet the causal relationship between motor and cognitive dimensions remain under debate (Coubard, 2011), we suggest that such a motor correlate may be observed for posture. In other words, we expected CD to improve motor flexibility (in other words to reduce motor stiffness) as compared to FP, which should take the form of higher stochastic activity in SDA and reduced determinism in RQA.

\section{MATERIALS AND METHODS PARTICIPANTS}

Forty-one French natives participated in the study, which was approved by the local ethics committee (Ecole des Hautes Etudes en Sciences Sociales, Paris). They were right-handed, had normal or corrected-to-normal vision, no known neurological disorders, and were unaware of the goal of the experiment. Table 1 details the participants' sex, age, body mass index (BMI, defined as the weight divided by the squared height in $\mathrm{kg} \mathrm{m}^{-2}$ ), years of education, and their score in the Mini-Mental State Examination (MMSE) for cognitive status (Folstein et al., 1975).

Sixteen participants aged 64-83 years made up the CD group, and 25 participants aged 59-86 years made up the FP group. The two groups were matched in sex $\left(\mathrm{Chi}^{2}<1\right)$, age $(t<1)$, BMI $\left(t_{39}=1.84, P>0.05\right)$, education $\left(t_{39}=1.38, P>0.05\right)$, and their score in the MMSE $(t<1)$.

The two groups were matched in past physical activity as appreciated by the reported years of practice, except for gymnastics. One participant had done 1 year of FP in the past, eight participants had done $4.0 \pm 5.4$ years of aqua gymnastics (no between-group difference, Mann-Whitney test, $Z<1$ ), and 19 of them had done $4.7 \pm 4.5$ years of gymnastics, with higher practice for the FP group (Mann-Whitney, $Z=-2.68, P<0.01$ ).

\section{APPARATUS}

Static posture was examined using a Techno-Concept platform (Céreste, France), which consisted of two dynamometric clogs, one for each foot, embedded in a board so that the angle made by the feet was $30^{\circ}$. The displacements of the CoP were recorded for $51.2 \mathrm{~s}$ and digitized at $40 \mathrm{~Hz}$ using a 16 bit analogical-digital converter.

Table 1 | Number (gender) or mean \pm SD (age, BMI, education, MMSE) for the groups of participants (CD, contemporary dance; FP, fall prevention).

\begin{tabular}{|c|c|c|}
\hline & CD & FP \\
\hline Sex (women/men) & $16 / 0$ & $23 / 2$ \\
\hline Age (years) & $73.7 \pm 5.5$ & $72.9 \pm 7.2$ \\
\hline BMI $\left(\mathrm{kg} \mathrm{m}^{-2}\right)$ & $26.9 \pm 4.8$ & $24.6 \pm 3.3$ \\
\hline Education (years) & $9.8 \pm 4.4$ & $7.8 \pm 3.9$ \\
\hline MMSE (/30) & $27.4 \pm 1.4$ & $27.2 \pm 2.1$ \\
\hline
\end{tabular}




\section{TRAINING PROGRAMS}

Participants were trained to CD or FP for 4.42 months in average. Participants did not have a choice in the training in which they were enrolled, which was set by the district where they lived in the Ile-de-France region. The training was conducted by a professional instructor and supervised by a senior teacher, each in their specialty (CD or FP). The frequency of the training was once a week, and each session lasted $1 \mathrm{~h}$. Music could be used during up to $50 \%$ of the session duration. Participants did not take part in other motor programs during the intervention period.

\section{Contemporary dance}

Contemporary dance focused on motor improvisation. (1) Opening was adapted to the needs of the group (e.g., variations of the action of walking, free dance on a popular music). (2) Warmup and preparation to dance. Body was awakened by passive and active movements of joints, and movements of muscular stretching promoting coordination, link between breath and movement, and body positioning and alignment. (3) Improvisation. Based on a theme or constraint (word, action, idea, object, music, or location), it was organized around four steps: (i) individual exploration of the theme; (ii) exploration in pair or more taking into account the others' presence; (iii) each group presented the work developed in (i) and (ii); (iv) participants improvised in a solo and developed a natural movement to express their own sensations. At steps (i) and (ii), the instructor suggested dance tools to favor exploration and use of each individual and of the exercise resources. (4) Closure. Cooling down by breath and massages. For a session, 5, 20, 30, and $5 \mathrm{~min}$ were respectively dedicated to the stages $1-4$.

\section{Fall prevention}

Fall prevention focused on balance and the development of lower limbs. A session was organized as follows. (1) Warm-up and stretching. (2) Development of visual, vestibular, kinaesthetic, and proprioceptive functions, through specific exercises, to optimize each function. (3) Workshops were organized around objects: as example, participants stepped over obstacles, walked on foam rubbers, on small bags of sand, on a rope, etc. The training emphasized motor skills ensuring postural stability, as well as accuracy and amplitude of movements. (4) Cooling down and stretching. The training was performed individually and in pairs. For a session, 10, 20,20 , and $10 \mathrm{~min}$ were respectively dedicated to the stages $1-4$.

\section{POSTURAL RECORDING}

Participants underwent postural recordings before and after the training intervention. In a quiet normal illuminated room, they stood in an upright posture on the platform, barefoot, and their arms comfortably at their sides, with the instruction to breathe normally and keep relaxed. Participants underwent four conditions: in the eyes closed condition, they wore a mask in front of their eyes enabling darkness; in the eyes open conditions, they fixated a black circular surface at eye level subtending $1.5^{\circ}$ of visual angle, at a distance of 600,150 , or $40 \mathrm{~cm}$ (Coubard, 2011). When necessary, participants wore their usual spectacle correction.

\section{POSTURAL MEASUREMENTS}

Raw data provided by the manufacturer software were preprocessed using home-made scripts under MAтLAв 7.0 (The MathWorks, USA). First and last of the 2048 samples were discarded as they exhibited artifacts due to respectively onset and offset of the recording, and only positions of the CoP in mediolateral $(x)$ and anteroposterior $(y)$ planes were kept for further analysis. An example of CoP displacements is illustrated in Figure 1A. We calculated statistic scores and performed dynamic analyses using home-made scripts under R (www.r-project.org).

\section{Statistic scores}

We measured the length (in millimeters, $\mathrm{mm}$ ), the confidence ellipse area $\left(\right.$ in $\mathrm{mm}^{2}$ ) that includes $90 \%$ of the positions of the $\mathrm{CoP}$, and the mean and variance velocities (in $\mathrm{mm} \mathrm{s}^{-1}$ ) of the CoP displacements. We also calculated the convex hull area (in $\mathrm{mm}^{2}$ ) including $100 \%$ of the positions of the CoP (Andrew, 1979; see Figure 1A), the Romberg quotient as the surface confidence ellipse eyes closed divided by the average one in the eyes open conditions, and the fractal dimension ratio (Chiari et al., 2000).

\section{Diffusion analysis}

We plotted the planar mean square displacement of the CoP $<\Delta r^{2}>$ in $\mathrm{mm}^{2}$ (where $r$ is the sum of the displacements in the mediolateral and anteroposterior planes, and the brackets means the average over time) as a function of time interval $\Delta t$ in seconds (see Figure 1B). We calculated the diffusion coefficients $D_{S}$ and $D_{\mathrm{L}}\left(\right.$ in $\mathrm{mm}^{2} \mathrm{~s}^{-1}$ ) for respectively the short- and long-term regions (before and after the critical point) from the slopes of linear-linear plots of $\left.<\Delta r^{2}\right\rangle$ vs. $\Delta t$ curves, and calculated the corresponding scaling exponents $H_{\mathrm{S}}$ and $H_{\mathrm{L}}$ from the log-log plots of such curves. We measured the coordinates of the critical point separating short- and long-term regions, defined as the critical time interval $\Delta t_{\mathrm{rc}}$ (in s) on the $x$ axis and the critical mean square displacement $<\Delta r^{2}>_{c}\left(\right.$ in $\mathrm{mm}^{2}$ ) on the $y$ axis (see Figure 1B).

\section{Recurrence quantification analysis}

We examined the local recurrence of data points in the reconstructed phase space. Following input parameters were chosen according to Webber and Zbilut's (2005) recommendations: time lag was set to $50 \mathrm{~ms}$ corresponding to two samples; the embedding dimension was set to 12 ; the radius was restricted to the values $2-3 \%$ of the mean distance between data points since $1 \%$ or $4-5 \%$ provided respectively not enough and too many recurrent points; the number of successive points to define a diagonal line segment was set to 3 . We measured the percentage of \%REC and of $\% \mathrm{DET}$, and the MAXL. We calculated the three measures separately for the $x$ and $y$ planes of the CoP fluctuations, and for radii equal to 2 and 3\%. An example of RQA plot is shown in Figure 1C.

\section{STATISTICAL ANALYSIS}

All measures were submitted to analyses of variance (ANOVAs) with Group (two levels: CD vs. FP) as between-participant factor, Period (two levels: pre-test vs. post-test), and Eye (two levels: eyes closed, eyes open) as within-participant factors. The training duration was entered as a covariate in all statistical analyses since it was higher in the CD group compared to the FP group ( $5.06 \pm 0.92$ vs. 

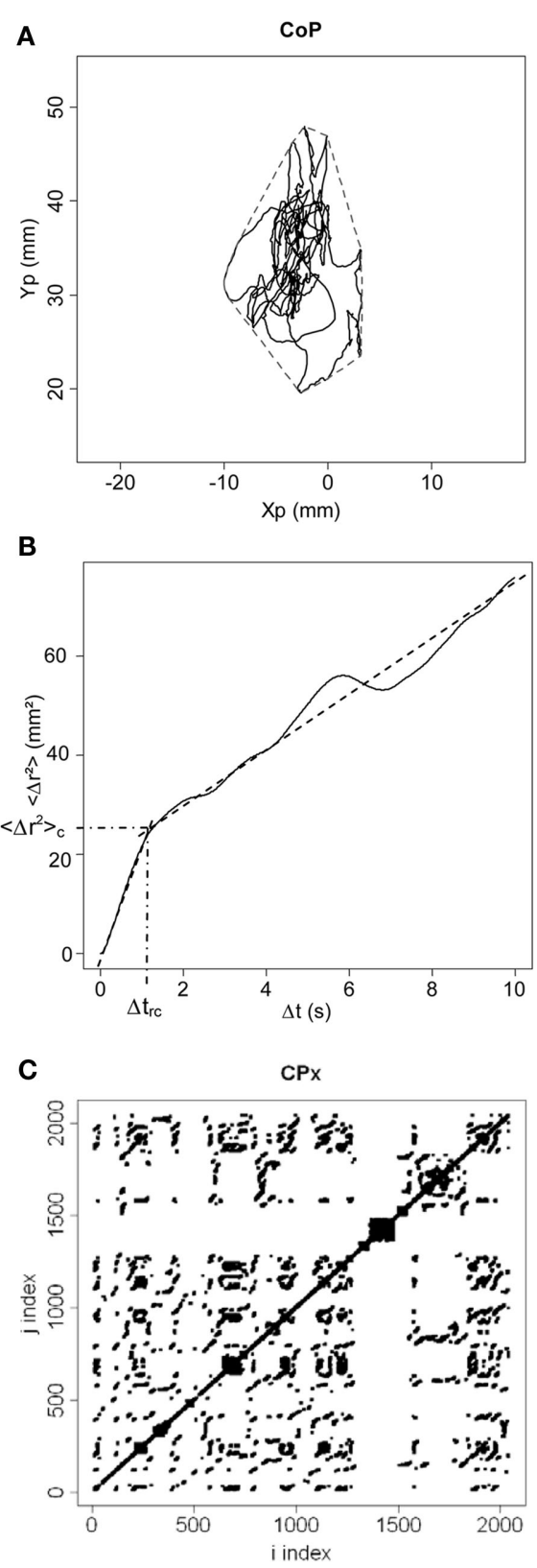

FIGURE 1 | (A) Statokinesigram of center-of-pressure (CoP) displacements. Anteroposterior displacements of the CoP (Yp) are plotted against mediolateral displacements $(X p)$ in millimeters $(\mathrm{mm})$. The convex hull area is shown in dotted line. (B) Stabilogram-diffusion plot. We show the mean square CoP displacement $\left.\left(<\Delta r^{2}\right\rangle\right)$ in $\mathrm{mm}^{2}$ as a function of time interval $(\Delta t)$ in seconds. Experimental data is shown in full line, and theoretical fitting for the first and second regressions is shown in dotted line. The critical point between the two regressions is indicated by its coordinates (emphasized by semi-dotted lines) on the $x$ axis $\left(\Delta t_{\mathrm{rc}}\right)$ and on the $y$ axis $\left(<\Delta r^{2}>_{c}\right)$. (C) Recurrence quantification analysis plot. In this example, the phase space is shown for mediolateral fluctuations (CPx) for a radius of $3 \%$. Thus, for a sphere of radius equal to $3 \%$ of the mean distance between data points of the phase space, we calculated for $i=1-N$ and $j=1-N$ (where $N$ is the total number of data points) the distance between data points $x(\mathrm{i})$ and $x(\mathrm{j})$, and darkened every recurrent point for which the distance was below the radius. For $i=j$, the distance is zero resulting in the central diagonal line.
$4.01 \pm 0.85$ months, respectively; $\left.t_{39}=3.73, P<0.001\right)$. Post hoc tests were calculated using Fisher's least significant difference (LSD) method. Critical results were corroborated by calculating more conservative post hoc tests using Newman-Keuls (NK) method. For critical results, we also calculated effects sizes using Cohen's measure defined as $\left(m_{\exp }-m_{\mathrm{ctrl}}\right) /\left[\left(\sigma_{\exp }+\sigma_{\mathrm{ctrl}}\right) / 2\right]$, where $m$ and $\sigma$ are respectively mean and SD for experimental (CD) and control (FP) groups. We used Statistica 7.0 (StatSoft, USA) for all analyses. Distributional information was given by standard errors (SE).

\section{RESULTS}

\section{STATISTIC SCORES}

Results are detailed in Table 2. Three-way ANOVAs with Group, Period, and Eye as factors showed neither main effect nor interaction for the length, the confidence ellipse, and convex hull areas, the mean and variance velocities, and the Romberg quotient. For fractal dimension, only the Group $\times$ Eye interaction was statistically significant $\left(F_{1,38}=6.02, P<0.05\right)$, due to a lower mean value eyes open in the CD group (LSD, $P<0.01$ ).

\section{DIFFUSION ANALYSIS}

Results are provided in Table 3. Three-way ANOVAs with Group, Period, and Eye as factors showed neither main effect nor interaction for the diffusion coefficient $D_{\mathrm{S}}$, the scaling exponents $H_{\mathrm{S}}$ and $H_{\mathrm{L}}$, and the critical mean square displacement $\left.<\Delta r^{2}\right\rangle_{\mathrm{c}}$. For the diffusion coefficient $D_{\mathrm{L}}$, we found a main effect of Period $\left(1.48\right.$ vs. $1.78 \mathrm{~mm}^{2} \mathrm{~s}^{-1}$ in pre- and post-test periods, respectively; $\left.F_{1,38}=4.57, P<0.05\right)$.

For the critical time interval $\Delta t_{\mathrm{rc}}$, we observed a main effect of Group ( 1.48 vs. $1.14 \mathrm{~s}$ in the $\mathrm{CD}$ and FP groups, respectively; $\left.F_{1,38}=6.84, P<0.05\right)$. Critical for our hypothesis, the Group $\times$ Period $\times$ Eye interaction was significant $\left(F_{1,38}=4.21\right.$, $P<0.05)$, with eyes open an increase between the pre- and posttest periods in the CD group ( 1.53 vs. 1.65 s; LSD, $P=0.030$; NK, $P=0.045)$ vs. a tendency for a decrease in the FP group (1.16 vs. $1.02 \mathrm{~s}$; LSD, $P=0.059$ ). With respect to effect sizes, Cohen's d values in the eyes open condition were 2.93 and 4.75 in pre- and post-test periods, respectively (see Figure $2 \mathbf{A}$ ).

\section{RECURRENCE QUANTIFICATION ANALYSIS}

Table 4 shows detailed results. In the mediolateral plane, threeway ANOVAs with Group, Period, and Eye as factors showed a main effect of Group for \%REC and a radius of $2 \%\left(F_{1,38}=9.90\right.$, $P<0.01)$, for $\%$ REC-3\% $\left(F_{1,38}=9.66, P<0.01\right)$, for MAXL$2 \%\left(F_{1,38}=11.8, P<0.01\right)$, and for MAXL-3\% $\left(F_{1,38}=6.95\right.$, $P<0.05)$ with higher mean values in the $\mathrm{CD}$ group, and a main effect of Period for \%REC-2\% $\left(F_{1,38}=5.41, P<0.05\right)$ with a higher value in the pre-test period. We observed a Group $\times$ Eye interaction for all measures except MAXL-2\% due to systematic higher mean values eyes open in the $\mathrm{CD}$ group (LSD, $P<0.05$ ), and a Period $\times$ Eye interaction for $\%$ REC- $\%$ $\left(F_{1,38}=5.65, P<0.05\right)$, and \%REC-3\% $\left(F_{1,38}=4.90, P<0.05\right)$ with only a tendency for higher mean values eyes open in the post-test period (LSD, $P>0.05$ ).

With regard to our hypothesis, we found a Group $\times$ Period interaction for $\%$ REC- $\%\left(F_{1,38}=4.34, P<0.05\right)$, which was due 
Table 2 | Mean \pm SE of statistic scores for the groups of participants (CD, contemporary dance; FP, fall prevention).

\section{Eyes closed}

\section{LENGTH (mm)}

Pre-test

Post-test

ELLIPSE AREA $\left(\mathrm{mm}^{2}\right)$

Pre-test

Post-test

HULL AREA $\left(\mathrm{mm}^{2}\right)$

Pre-test

Post-test

MEAN VELOCITY $\left(\mathrm{mm} \mathrm{s}^{-1}\right)$

Pre-test

Post-test

VARIANCE VELOCITY $\left(\mathrm{mm} \mathrm{s}^{-1}\right)$

Pre-test

Post-test

FRACTAL DIMENSION

Pre-test

Post-test

ROMBERG QUOTIENT

Pre-test

Post-test
CD

FP

$703.7 \pm 109.0$

$695.9 \pm 74.4$

$345.3 \pm 168.4$

$346.8 \pm 136.7$

$527.8 \pm 260.7$

$445.6 \pm 139.4$

$13.8 \pm 2.13$

$13.6 \pm 1.45$

$138.5 \pm 50.8$

$133.4 \pm 39.9$

$1.68 \pm 0.04$

$1.69 \pm 0.03$

$1.70 \pm 0.02$

YES OPEN

$\begin{array}{ll}1.08 \pm 0.12 & 2.03 \pm 0.18 \\ 2.12 \pm 0.79 & 1.70 \pm 0.18\end{array}$

$1.70 \pm 0.18$

1.80

0.187

Eyes open

CD

$496.6 \pm 55.5$

$440.0 \pm 29.6$

$308.6 \pm 145.3$

$162.9 \pm 21.7$

$160.9 \pm 28.7$

1.04

0.314

$402.3 \pm 179.6$

$231.3 \pm 67.0$

$235.8 \pm 43.7$

1.61

0.212

$9.70 \pm 1.09 \quad 10.5 \pm 1.09$

$8.60 \pm 0.58 \quad 9.80 \pm 0.69$

$<1$

$61.6 \pm 22.1$

$62.9 \pm 17.7$

$49.3 \pm 8.24$

$1.72 \pm 0.02$

$1.68 \pm 0.02$

$1.64 \pm 0.03$
$1.64 \pm 0.03$

$<1$

ANOVAs' $F$ and $P$ values are those of the third-order interaction (except for the Romberg quotient for which $F$ and $P$ values are those of the second-order interaction).

Table 3 | Mean \pm SE of diffusion analysis for the groups of participants (CD, contemporary dance; FP, fall prevention).

\section{Eyes closed}

CD FP

\section{$D_{S}\left(\mathrm{~mm}^{2} \mathrm{~s}^{-1}\right)$}

Pre-test

Post-test

$D_{\mathrm{L}}\left(\mathrm{mm}^{2} \mathrm{~s}^{-1}\right)$

Pre-test

Post-test

$\boldsymbol{H}_{\mathrm{S}}$

Pre-test

Post-test

$\boldsymbol{H}_{\mathrm{L}}$

Pre-test

Post-test

$<\Delta r^{2}>_{c}\left(\mathrm{~mm}^{2}\right)$

Pre-test

Post test

$\Delta$ trc (s)

Pre-test

Post test

$44.7 \pm 23.2$

$30.8 \pm 8.08$

$1.48 \pm 0.80$

$2.09 \pm 0.91$

$0.688 \pm 0.02$

$0.689 \pm 0.019$

$0.034 \pm 0.011$

$0.044 \pm 0.011$

$108.7 \pm 53.0$

$88.4 \pm 35.9$

$1.41 \pm 0.16$

$1.32 \pm 0.16$ periods.

\section{Eyes open}

CD

FP

$\boldsymbol{F}$

$\boldsymbol{P}$

$46.6 \pm 14.3$

\section{$22.6 \pm 11.3$}

$11.1 \pm 1.37$

$18.5 \pm 6.80$

$14.6 \pm 3.02$

$1.90 \pm 0.69$

$1.69 \pm 0.24$

$1.24 \pm 0.25$

$1.49 \pm 0.25$

$<1$

$\begin{array}{ll}0.648 \pm 0.019 & 0.657 \pm 0.015\end{array}$

$0.652 \pm 0.019$

$0.665 \pm 0.012$

$<1$

$0.081 \pm 0.013$

$0.085 \pm 0.009$

$0.104 \pm 0.007$

$<1$

$0.095 \pm 0.009$

$32.9 \pm 9.66$

$27.0 \pm 5.17$

$32.4 \pm 4.92$

$1.16 \pm 0.11$

$1.02 \pm 0.06$

4.21

0.047

$\begin{array}{ll}1.53 \pm 0.15 & 1.16 \pm 0.11 \\ 1.65 \pm 0.22 * & 1.02 \pm 0.06\end{array}$




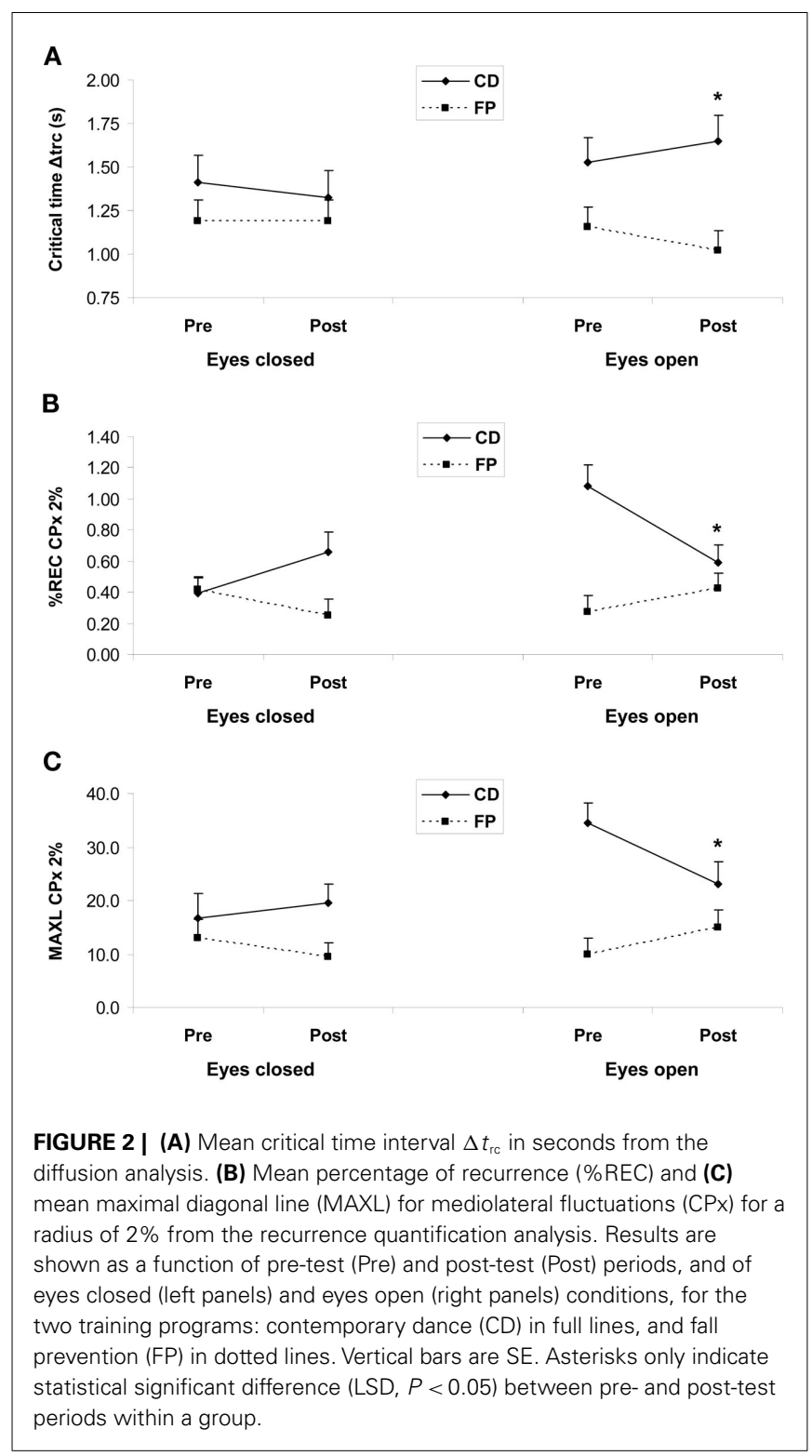

to a tendency for a decrease between pre- and post-test periods in the CD group (respectively 0.737 and 0.623 ; LSD, $P>0.05$ ) whereas no change occurred in the FP group (0.343 and 0.339; LSD, $P>0.05)$. The Group $\times$ Period $\times$ Eye interaction was significant for all measures $(P<0.05)$, with a systematic pattern that is illustrated in Figures 2B,C. In the eyes open condition, the mean value decreased in the CD group for all measures (\%REC-2\%, LSD, $P=0.002$, NK, $P=0.002$; \%REC-3\%, LSD, $P=0.005$, NK, $P=0.006$; MAXL-2\%, LSD, $P=0.012$, NK, $P=0.006)$, whereas it increased in the FP group for all measures (LSD, $P<0.05$ only for $\%$ DET-2\%; see Figures 2B,C). To illustrate effect sizes, Cohen's $d$ values for \%REC-2\% in the eyes open condition were 6.57 and 1.54 in pre- and post-test periods, respectively (see Figure 2B). For MAXL-2\%, Cohen's $d$ values eyes open were 7.27 and 2.17 in preand post-test periods (see Figure 2C). Eyes closed, the pattern was the reverse: an increase between the two periods in the CD group
(LSD, $P<0.05$ only for $\%$ DET-2\%) vs. a decrease in the FP group (LSD, $P<0.05$ only for MAXL-3\%).

In the anteroposterior plane, three-way ANOVAs with Group, Period, and Eye as factors showed a main effect of Eye for $\%$ REC-2\% $\left(F_{1,38}=4.19, P<0.05\right)$ and $\%$ REC-3\% $\left(F_{1,38}=4.16\right.$, $P<0.05)$ with higher mean values eyes open. As in the mediolateral plane, we observed a Group $\times$ Eye interaction for all measures as a result of higher mean values eyes open in the CD group (LSD, $P<0.05$ except for \%REC-3\% and \%DET-3\%).

With respect to our expectancy, a Group $\times$ Period interaction was found for $\%$ REC-2\% $\left(F_{1,38}=4.10, P<0.05\right)$, as a result of a tendency for a decrease vs. an increase in mean values between the pre- and post-test periods in the CD vs. the FP groups, respectively (the difference between the two periods failed to reach significance for the two groups). The Group $\times$ Period interaction was also significant for MAXL-2\% $\left(F_{1,38}=5.50, P<0.05\right)$, for which the decrease in the CD group was insignificant contrary to the increase in the FP group (LSD, $P<0.05$ ). Finally, there was no third-order interaction for any measure.

\section{DISCUSSION}

The main findings of this study were that the practice of $\mathrm{CD}$ in older adults enhanced the critical time interval in SDA, and reduced recurrence and mathematical stability in RQA, as compared to practice of FP which tended to induce reverse patterns. One limitation of this study was that the two groups did not perform equally in the pre-test period. The initial higher level in gymnastics in the FP group may have participated in betweengroup disparity and further research is needed to corroborate our observations.

In aging, previous cross-sectional studies have suggested that social dance may benefit balance, postural stability, and walking pattern (Verghese, 2006; Zhang et al., 2008), and intervention studies have evidenced how aerobic (Shigematsu et al., 2002; Hui et al., 2009), Laban-based (Hamburg and Clair, 2003), or jazz (Alpert et al., 2009) dance improve balance using clinical (Shigematsu et al., 2002; Hamburg and Clair, 2003; Hui et al., 2009) or laboratory (Alpert et al., 2009) measures. Our study is the first one to examine the effects of $\mathrm{CD}$ on motor control using posturography and dynamic analyses of static posture before/after the intervention, which enabled us to provide further insight into the underlying mechanisms by which dance influences postural control (Judge, 2003).

For Collins and De Luca (1993), human being in quiet standing is viewed not as an inverted pendulum but a pinned-polymer whose $\mathrm{CoP}$ displacements result from a blend of stochastic and deterministic processes. Over short-term interval, the postural control system would utilize open-loop mechanisms dominated by randomness, before closed-loop mechanisms would be called into play with a prevalence of deterministic control. Here we showed that $\mathrm{CD}$ delayed the point at which the postural system switches from open- to closed-loop control, suggesting that CD enlarged the initial temporal window for motor stochastic processes. A previous study reported age-related increased critical mean square displacement and critical time interval resulting in a short-term interval higher slope, which the authors interpreted as enhanced postural stiffness with age (Collins et al., 1995). In our CD group, 
Table 4 | Mean \pm SE of recurrence quantification analysis for the groups of participants (CD, contemporary dance; FP, fall prevention).

\begin{tabular}{|c|c|c|c|c|c|c|}
\hline & \multicolumn{2}{|c|}{ Eyes closed } & \multicolumn{4}{|c|}{ Eyes open } \\
\hline & CD & FP & CD & FP & $\boldsymbol{F}$ & $P$ \\
\hline \multicolumn{7}{|c|}{$\%$ REC $\times 2$} \\
\hline Pre-test & $0.392 \pm 0.116$ & $0.418 \pm 0.070$ & $1.08 \pm 0.227$ & $0.269 \pm 0.040$ & & \\
\hline Post-test & $0.658 \pm 0.183$ & $0.253 \pm 0.063$ & $0.589 \pm 0.122^{*}$ & $0.425 \pm 0.089$ & 20.8 & 0.000 \\
\hline \multicolumn{7}{|c|}{ \%REC $\times 3$} \\
\hline Post-test & $1.80 \pm 0.415$ & $0.880 \pm 0.152$ & $1.62 \pm 0.253^{*}$ & $1.34 \pm 0.201$ & 19.6 & 0.000 \\
\hline \multicolumn{7}{|c|}{ \%DET $\times 2$} \\
\hline Pre-test & $69.0 \pm 3.25$ & $69.8 \pm 2.64$ & $78.1 \pm 2.18$ & $65.5 \pm 2.49$ & & \\
\hline Post-test & $74.1 \pm 2.58^{*}$ & $68.6 \pm 1.65$ & $74.1 \pm 2.35$ & $70.2 \pm 2.14^{*}$ & 16.7 & 0.000 \\
\hline \multicolumn{7}{|c|}{ \%DET $\times 3$} \\
\hline Post-test & $19.6 \pm 4.64$ & $9.45 \pm 2.05$ & $23.1 \pm 4.67^{*}$ & $15.0 \pm 2.89$ & 9.58 & 0.004 \\
\hline \multicolumn{7}{|c|}{ MAXL $x 3$} \\
\hline Pre-test & $33.4 \pm 7.46$ & $41.1 \pm 5.59$ & $66.0 \pm 6.96$ & $32.8 \pm 4.00$ & & \\
\hline Post-test & $40.9 \pm 7.08$ & $26.3 \pm 4.02 *$ & $55.3 \pm 8.01$ & $39.8 \pm 4.61$ & 9.28 & 0.004 \\
\hline \multicolumn{7}{|c|}{ \%REC y 2} \\
\hline Pre-test & $0.420 \pm 0.120$ & $0.332 \pm 0.069$ & $0.690 \pm 0.218$ & $0.308 \pm 0.054$ & & \\
\hline Post-test & $0.353 \pm 0.080$ & $0.389 \pm 0.076$ & $0.538 \pm 0.124$ & $0.389 \pm 0.056$ & 1.08 & 0.304 \\
\hline \multicolumn{7}{|c|}{ \%REC y 3} \\
\hline Pre-test & $1.22 \pm 0.268$ & $1.01 \pm 0.170$ & $1.72 \pm 0.483$ & $0.941 \pm 0.128$ & & \\
\hline Post-test & $1.02 \pm 0.181$ & $1.15 \pm 0.177$ & $1.43 \pm 0.284$ & $1.16 \pm 0.130$ & $<1$ & - \\
\hline \multicolumn{7}{|c|}{ \%DET y 2} \\
\hline Post-test & $14.5 \pm 3.75$ & $18.2 \pm 3.31$ & $22.0 \pm 4.98$ & $15.6 \pm 2.32$ & $<1$ & - \\
\hline \multicolumn{7}{|c|}{ MAXL y 3} \\
\hline Pre-test & $32.8 \pm 6.43$ & $28.3 \pm 4.27$ & $45.1 \pm 8.45$ & $33.7 \pm 4.35$ & & \\
\hline Post-test & $29.6 \pm 4.49$ & $35.5 \pm 4.33$ & $49.5 \pm 7.01$ & $36.1 \pm 4.10$ & 2.20 & 0.146 \\
\hline
\end{tabular}

ANOVAs' $F$ and $P$ values are those of the third-order interaction. Asterisks only indicate statistical significant difference $(L S D, P<05)$ between pre- and post-test periods.

post-test increased critical time interval without any change in critical mean square displacement resulted in lower short-term interval slope, which suggests reduced postural stiffness after CD training.

Further insight was provided by RQA approach (Riley et al., 1999) allowing us to quantify the degree of recurrence, determinism, and mathematical stability of CoP displacements. CD reduced both recurrence and mathematical stability suggesting that CoP displacements were less likely to repeat themselves over time and that their dynamics were more flexible, whereas FP yielded the opposite tendency. Such a pattern was almost visible for mediolateral displacements of the CoP, which we explain from a biomechanical viewpoint by the fact that the base of support for upright stance is wider in the mediolateral plane than in the anteroposterior one.

Taken together, we propose that CD promoted stochastic postural control of older adults, by providing more time to random postural processes, decreasing repeatability and increasing flexibility of postural oscillations. In both SDA and RQA, the effects were observed eyes open, which may be due to the fact that motor activities were mostly practiced eyes open. Since we measured static posture, we suggest that $\mathrm{CD}$ influenced the flexibility of the central postural system per se, resulting in higher complexity in the mathematical sense, i.e., higher adaptability in the physiological 
sense. Such effect may have been caused by improvisation which favored creativity and constant adaptation to constraints in space, time, interaction with other dancers, whereas FP based on more stereotyped behaviors tended to produce opposite effects.

Suggesting that CD improves postural flexibility in older adults, the present study completes a previous report (Coubard et al., 2011) showing that CD improves cognitive flexibility in aging. How motor and cognitive dimensions interact to yield parallel effects needs to be further investigated by measuring motor and attentional control in the same participants undergoing such training programs. In the meanwhile, we suggest a cortical-subcortical loop hypothesis to account for the improvement of postural flexibility. Motor control involves extensive areas of the central nervous system from the spinal cord to the cerebral cortex: globus pallidus, putamen, caudate nucleus, thalamus, substantia nigra, subthalamic nucleus, cerebellum, reticular formation, vestibular nuclei. At a higher level, the supplementary motor cortex, the frontal eye fields, the dorsolateral prefrontal cortex play a supramotor role in, respectively, preparing (Jenkins et al., 2000), monitoring (Schall, 2004), and controlling (Rowe et al., 2000) the movement to be produced by the primary motor cortex.

\section{REFERENCES}

Alexander, G. E., DeLong, M. R., and Strick, P. L. (1986). Parallel organization of functionally segregated circuits linking basal ganglia and cortex. Annu. Rev. Neurosci. 9, 357-381.

Alpert, P. T., Miller, S. K., Wallmann, H., Havey, R., Cross, C., Chevalia, T., Gillis, C. B., and Kodandapari, K. (2009). The effect of modified jazz dance on balance, cognition, and mood in older adults. J. Am. Acad. Nurse Pract. 21, 108-115.

American Geriatrics Society, British Geriatrics Society, and American Academy of Orthopaedic Surgeons Panel on Falls Prevention. (2001). Guideline for the prevention of falls in older persons. J. Am. Geriatr. Soc. 49, 664-672.

Andrew, A. M. (1979). Another efficient algorithm for convex hulls in two dimensions. Inf. Process. Lett. 9, 216-219.

Benedetti, M. G., Berti, L., Presti, C., Frizziero, A., and Giannini, S. (2008). Effects of an adapted physical activity program in a group of elderly subjects with flexed posture: clinical and instrumental assessment. J. Neuroeng. Rehabil. 5, 32.

Berg, K., Wood-Dauphinee, S., and Williams, J. I. (1995). The balance scale: reliability assessment with elderly residents and patients with an acute stroke. Scand. J. Rehabil. Med. 27, 27-36.

Bherer, L., Belleville, S., and Hudon, C. (2004). Le déclin des fonctions exécutives au cours du vieillissement normal, dans la maladie d'Alzheimer et dans la démence frontotemporale. Psychol. Neuropsychiatr. Vieil. 2, 181-189.

Chiari, L., Cappello, A., Lenzi, D., and Della Croce, U. (2000). An improved technique for the extraction of stochastic parameters from stabilograms. Gait Posture 12, 225-234.

Collins, J. J., and De Luca, C. J. (1993). Open-loop and closed-loop control of posture: a random-walk analysis of center-of-pressure trajectories. Exp. Brain Res. 95, 308-318.

Collins, J. J., and De Luca, C. J. (1995). The effects of visual input on openloop and closed-loop postural control mechanisms. Exp. Brain Res. 103, 151-163.

Collins, J. J., De Luca, C. J., Burrows, A., and Lipsitz, L. A. (1995). Age-related changes in open-loop and closedloop postural control mechanisms. Exp. Brain Res. 104, 480-492.

Coubard, O. A. (2011). Les neurones des mouvements des yeux. Saarbrücken: Editions Universitaires Européennes.

Coubard, O. A., Duretz, S., Lefebvre, V., Lapalus, P., and Ferrufino, L. (2011). Practice of contemporary dance improves cognitive flexibility in aging. Front. Aging Neurosci. 3:13. doi: 10.3389/fnagi.2011.00013

Day, L., Fildes, B., Gordon, I., Fitzharris, M., Flamer, H., and Lord, S. (2002). Randomised factorial trial of falls prevention among older people living in their own homes. $B M J$ $325,128$.

It is likely that this motor network together with corticalsubcortical loops linking the cerebral cortex to basal ganglia (Alexander et al., 1986) may be involved in motor activities such as $\mathrm{CD}$ and FP. However, CD may require higher attentional demand than FP due to the practice of improvisation. In such a way, the prefrontal-subcortical interaction may have been recruited with higher frequency and intensity, resulting in enhanced motor flexibility. Taken together with the report by Coubard et al. (2011), this study suggests that $\mathrm{CD}$ induces changes at both postural and attentional levels, which may share common characteristics.

To conclude, the results of this study suggested that $\mathrm{CD}$ practice favors flexible postural control in older adults. Taken together with good acceptance, adherence, and moderate intensity associated with this practice, we recommend CD to develop motor plasticity not only in normal aging but also in pathological conditions with motor stiffness (Schmit et al., 2006).

\section{ACKNOWLEDGMENTS}

Results were presented at the 6th International Conference on the Arts in Society (Berlin, Germany, 2011). The authors thank ADAL (Paris) for allowing the assessment of some participants.

de Bruin, E. D., and Schmidt, A. (2010). Walking behaviour of healthy elderly: attention should be paid. Behav. Brain Funct. 6, 59.

Famula, A., Nowotny-Czupryna, O. Brzek, A., Nowotny, J., and Kita, B. (2008). Telereceptive and proprioceptive control of balance vs. body stability in elderly people. Ortop. Traumatol. Rehabil. 10, 384-395.

Folstein, M. F., Folstein, S. E., and McHugh, P. R. (1975). "Mini-mental state.” A practical method for grading the cognitive state of patients for the clinician. J. Psychiatr. Res. 12 , 189-198.

Hamburg, J., and Clair, A. A. (2003). The effects of a laban-based movement program with music on measures of balance and gait in older adults. Activ. Adapt. Aging 28, 17-33.

Horak, F. B. (2006). Postural orientation and equilibrium: what do we need to know about neural control of balance to prevent falls? Age Ageing 35, ii7-iil1.

Hui, E., Chui, B. T., and Woo, J. (2009). Effects of dance on physical and psychological well-being in older persons. Arch. Gerontol. Geriatr. 49, e45-e50.

Jenkins, I. H., Jahanshahi, M., Jueptner, M., Passingham, R. E., and Brooks, D. J. (2000). Self-initiated versus externally triggered movements. II. The effect of movement predictability on regional cerebral blood flow. Brain 123, 1216-1228.

Judge, J. O. (2003). Balance training to maintain mobility and prevent disability. Am. J. Prev. Med. 25, 150-156.

King, M. B., Whipple, R. H., Gruman, C. A., Judge, J. O., Schmidt, J. A., and Wolfson, L. I. (2002). The performance enhancement project: improving physical performance in older persons. Arch. Phys. Med. Rehabil. 83, 1060-1069.

Kristinsdottir, E. K., Fransson, P. A., and Magnusson, M. (2001). Changes in postural control in healthy elderly subjects are related to vibration sensation, vision and vestibular asymmetry. Acta Otolaryngol. 121, 700-706.

Lord, S. R. (2006). Visual risk factors for falls in older people. Age Ageing 35, ii42-ii45.

Nashner, L. M. (1976). Adapting reflexes controlling the human posture. Exp. Brain Res. 26, 59-72.

Rajah, M. N., and D'Esposito, M. (2005). Region-specific changes in prefrontal function with age: a review of PET and fMRI studies on working and episodic memory. Brain 128, 1964-1983.

Raz, N., and Rodrigue, K. M. (2006). Differential aging of the brain: patterns, cognitive correlates and modifiers. Neurosci. Biobehav. Rev. 30, 730-748.

Riley, M. A., Balasubramaniam, R., and Turvey, M. T. (1999). Recurrence quantification analysis of postural fluctuations. Gait Posture 9, 65-78.

Robertson, M. C., Gardner, M. M., Devlin, N., McGee, R., and Campbell, A. J. (2001). Effectiveness and economic evaluation of a nurse 
delivered home exercise programme to prevent falls. 2: controlled trial in multiple centres. BMJ 322, 701-704.

Rossiter-Fornoff, J. E., Wolf, S. L., Wolfson, L. I., and Buchner, D. M. (1995). A cross-sectional validation study of the FICSIT common data base static balance measures. Frailty and injuries: cooperative studies of intervention techniques. J. Gerontol. A Biol. Sci. Med. Sci. 50, M291-M297.

Rowe, J. B., Toni, I., Josephs, O., Frackowiak, R. S., and Passingham, R. E. (2000). The prefrontal cortex: response selection or maintenance within working memory? Science 288, 1656-1660.

Rubenstein, L. Z. (2006). Falls in older people: epidemiology, risk factors and strategies for prevention. Age Ageing 35, ii37-ii41.

Schall, J. D. (2004). On the role of frontal eye field in guiding attention and saccades. Vision Res. 44, 1453-1467.
Schmit, J. M., Regis, D. I., and Riley, M. A. (2005). Dynamic patterns of postural sway in ballet dancers and track athletes. Exp. Brain Res. 163, 370-378.

Schmit, J. M., Riley, M. A., Dalvi, A., Sahay, A., Shear, P. K., Shockley, K. D., and Pun, R. Y. (2006). Deterministic center of pressure patterns characterize postural instability in Parkinson's disease. Exp. Brain Res. 168, 357-367.

Schultz, A. B. (1995). Muscle function and mobility biomechanics in the elderly: an overview of some recent research. J. Gerontol. A Biol. Sci. Med. Sci. 50, 60-63.

Shigematsu, R., Chang, M., Yabushita, N., Sakai, T., Nakagaichi, M., Nho, H., and Tanaka, K. (2002). Dancebased aerobic exercise may improve indices of falling risk in older women. Age Ageing 31, 261-266.

Theill, N., Martin, M., Schumacher, V., Bridenbaugh, S. A., and Kres- sig, R. W. (2011). Simultaneously measuring gait and cognitive performance in cognitively healthy and cognitively impaired older adults: the Basel motor-cognition dual-task paradigm. J. Am. Geriatr. Soc. 59, 1012-1018.

Verghese, J. (2006). Cognitive and mobility profile of older social dancers. J. Am. Geriatr. Soc. 54, 1241-1244.

Webber, C. L., and Zbilut, J. P. (2005) "Reccurrence quantification analysis of nonlinear dynamical systems," in Tutorials in Contemporary Nonlinear Methods for the Behavioral Sciences, eds M. A. Riley and G. C. Van Orden, 26-94. Available at: http:// www.nsf.gov/sbe/bcs/pac/nmbs/ nmbs.jsp

Zhang, J. G., Ishikawa-Takata, K., Yamazaki, H., Morita, T., and Ohta, T. (2008). Postural stability and physical performance in social dancers. Gait Posture 27, 697-701.
Conflict of Interest Statement: The authors declare that the research was conducted in the absence of any commercial or financial relationships that could be construed as a potential conflict of interest.

Received: 14 May 2011; accepted: 08 December 2011; published online: 29 December 2011.

Citation: Ferrufino L, Bril B, Dietrich $G$, Nonaka $T$ and Coubard $O A$ (2011) Practice of contemporary dance promotes stochastic postural control in aging. Front. Hum. Neurosci. 5:169. doi: 10.3389/fnhum.2011.00169

Copyright (C) 2011 Ferrufino, Bril, Dietrich, Nonaka and Coubard. This is an open-access article distributed under the terms of the Creative Commons Attribution Non Commercial License, which permits non-commercial use, distribution, and reproduction in other forums, provided the original authors and source are credited. 